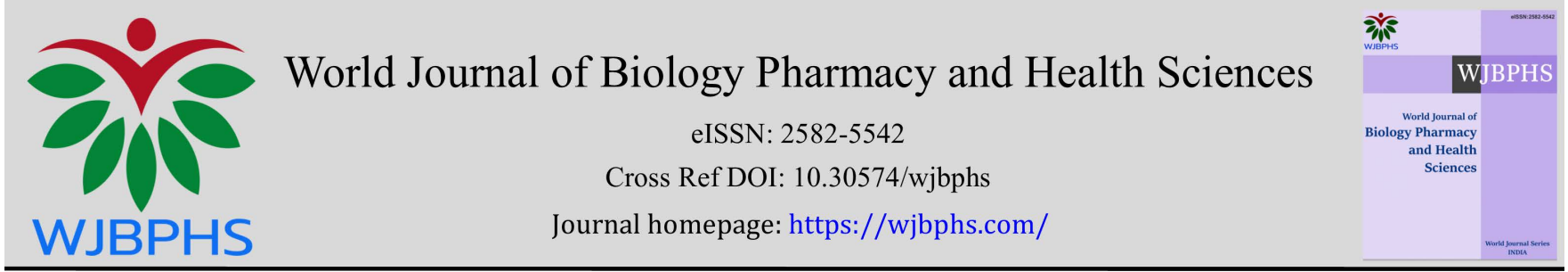

(RESEARCH ARTiCLE)

\title{
Incident, pattern and trends of scabies on randomly selected secondary schools' students in Anambra State, Nigeria
}

\author{
Nweze Kenneth Emeka 1, ${ }^{*}$, Ekekwe Evelyn Nkechi 2, Anaebonam Emeka 1, Okeke Chimaobi 1, Eze Chinwe \\ Catherine ${ }^{3}$ and Onyemeka Regland Michael ${ }^{4}$ \\ ${ }^{1}$ Department of Biological Sciences, Chukwuemeka Odumegwu Ojukwu University, Anambra, Nigeria. \\ 2 Department of Medical Laboratory Sciences, Nnamdi Azikiwe University, Nnewi, Anambra, Nigeria. \\ ${ }^{3}$ Department of Microbiology, Federal University of Technology, Owerri, Nigeria. \\ ${ }^{4}$ Department of Botany, Lagos State University, Lagos, Nigeria.
}

World Journal of Biology Pharmacy and Health Sciences, 2021, 07(03), 019-029

Publication history: Received on 01 August 2021; revised on 08 September 2021; accepted on 10 September 2021

Article DOI: https://doi.org/10.30574/wjbphs.2021.7.3.0090

\begin{abstract}
This study explored the determinants of Scabies infections in Secondary Schools across Anambra State to understand the dynamics and identify measures that will help reduce disease burden. A survey of Scabies infection was conducted on 5000 Students selected from fifty (50) randomly selected secondary schools in Anambra State. Focus group discussions, direct clinical observations and microscopic examinations were employed in this study. Data were categorized based on clinical features and was analysed using statistical package for social sciences (SPSS). The result revealed itching to be the most prevalent in both the males (23.69\%) and females $10.93 \%)$ followed by sleeping disturbances in males (15.40\%) and females (7.02\%). The findings also revealed that the distribution of scabies based on topographical locations and lesions were more prone to abdomen, inter-digital, legs, elbows, wrists and armpits than other parts of the body in both the male and female students examined. The risk factors associated with scabies infection in this research include sharing of beds, pillows, clothes and overcrowding which had a big effect on the infestation while others such as bathing habits, use of soaps had little effect. The majority of the participant was not aware of the real causes of scabies. Skin-to-skin contact was recorded as the most prevalent mode of transmission. On the treatment, most students patronize traditional medicine dealers, few consults patent medicine dealers, physicians and pharmacists. Public health enlightenment campaigns and school/community education programs may help in controlling these emerging epidemics in Anambra State and Nigeria in general.
\end{abstract}

Keywords: Scabies; Epidemic; Risk-factors; Prevalent

\section{Introduction}

Scabies refers to the various skin lesions produced by female mites, and their eggs and scybala that are deposited in the epidermis, leading to a delayed-type hypersensitivity reaction. Scabies ranked second to Tinea infections as the commonly observed childhood skin diseases in several studies (Figure 1) [1]. Although the infectious agent is ubiquitous, it is endemic in impoverished communities, such as underprivileged suburban villages, where up to $9 \%$ of the population and $19 \%$ of those attending a primary healthcare centre are infested. By contrast, in industrialized countries, outbreaks occur in hospitals and other institutions. Despite common belief, scabies is only infrequently acquired from contaminated fomites (e.g clothing, towels, and bedding) [2].

\footnotetext{
* Corresponding author: Nweze Kenneth Emeka

Department of Biological Sciences, Chukwuemeka Odumegwu Ojukwu University, Anambra, Nigeria. 
Scabies is an ectoparasite infestation. It is caused by the mite Sarcoptes scabiei variety hominis and transmitted by person-to-person contact [3]. Scabies was first described more than 2500 years ago [4]. Scabies was referred to in the Old Testament as lice in the flesh and by Aristotle [5]. But it was not until 1687 that the causative organism was identified by Bonomo and Cestoni using light microscopy [6].

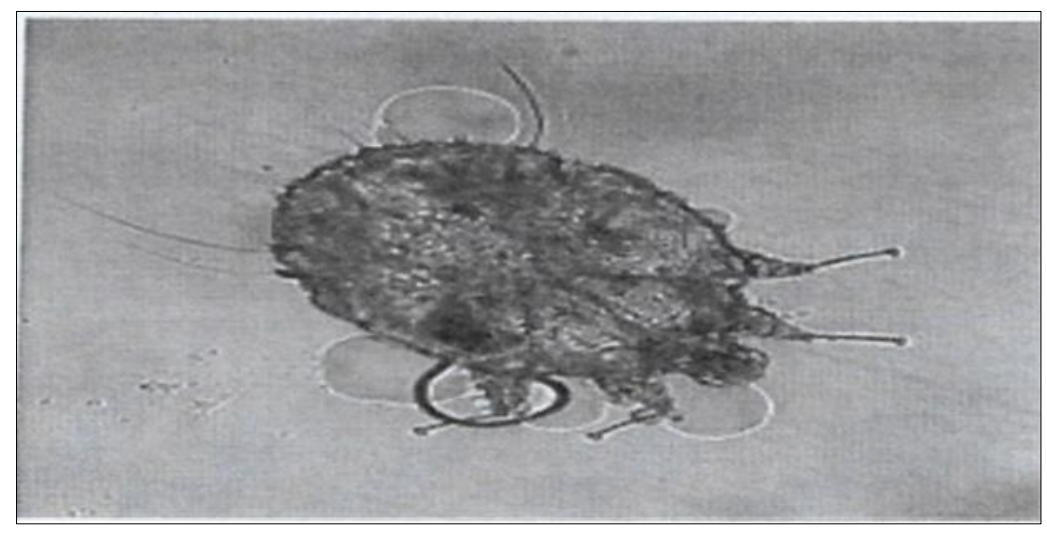

Figure 1 Human scabies mite seen under an optical microscope (x20)

The Italian biologists Giovanni Cosimo Bonomo and Diacinto Cestoni showed in the 17th century that scabies is caused by Sarcoptes scabiei; this discovery of the itch mite in 1687 marked scabies as the first disease of humans with a known microscopic causative agent [5] and [7]. The disease produces intense, itchy skin rashes when the impregnated female tunnels into the stratum corneum of the skin and deposits eggs in the burrow. The larvae, which hatch in three to 10 days, move about on the skin, moult into a nymphal stage and then mature into adult mites. The adult mites live three to four weeks in the host's skin [8] and [9].

Scabies, which is listed as one of the Neglected Tropical diseases, is associated with poverty and overcrowding and affects families especially the most vulnerable, with its greatest impact on young children; it may be characterized by a cycle of infection with peaks and troughs of disease prevalence [10] and [11]. Therefore this study explored the determinants of infections in Secondary Schools across the state to understand the disease dynamics and identify measures that will help reduce disease burden.

\section{Material and methods}

\subsection{Study Area}

The study was conducted in Secondary Schools in Anambra State, South-Eastern Nigeria with students as the target population. Anambra State has 21 local government areas with over 300 public and private secondary schools.

\subsection{Study Design}

Fifty (50) Secondary Schools were randomly selected from across the 21 local government areas to participate in the study. 5000 students were selected from across the schools to participate in the study. Of this sample, 2000 male and 3000 female students were examined respectively.

The data on knowledge, attitude and perception (KAP) were determined using structural questionnaires, Focus Group Discussion, In-debt interviews and direct clinical observations. For this study; Scabies was defined based on a symptomatic description with typical skin lesions such as papules, vesicular rash and nodules and with pruritus that intensified at night. The students were carefully examined clinically for scabies infestation by the clinical research team including a Dermatologist. This is of paramount importance to differentiate scabies from other skin infections like eczema, impetigo, Tinea corpovis (Ringworm) and psoriasis. The students were then categorised based on symptoms experienced (clinical features).

\subsection{Data Analysis and Presentation}

The data that was obtained from this study were analysed using Statistical Package for Social Sciences (SPSS) for windows version 20.0 (SPSS. Inc., Chicago 11, USA). The results are visualized as graph representations and presented based on clinical features. 


\section{Results}

A total number of five thousand (5000) students were examined for scabies infestation amongst the randomly selected secondary schools from the 21 local government areas in Anambra State Nigeria. Of this sample, 2000 male and 3000 female students were examined respectively based on the clinical features.

\subsection{Distribution of scabies infection among male secondary school students examined based on clinical features}

The result obtained showed that the male students with itching as clinical features had the highest prevalence rates of $23.6 \%$ followed by sleeping disturbances with $15.40 \%$ and topographical locations of lesions with $13.60 \%$ while Lymphadenopathy had 5.60\% (Figure 2).

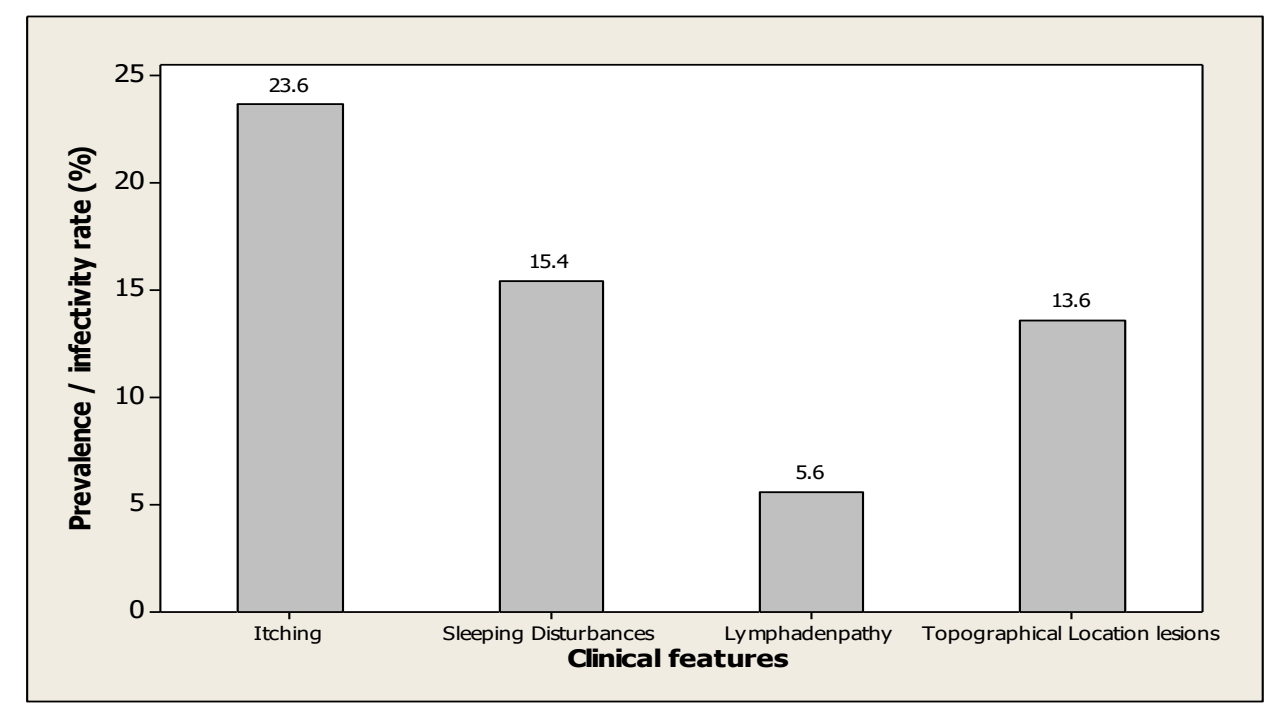

Figure 2 Bar Chart showing the distributions of scabies infection among male secondary school students examined based on clinical features

\subsection{Distribution of scabies infection among female secondary school students examined based on clinical features}

The result showed that the female students with itching clinical features had the highest prevalence rate of $10.93 \%$ followed by sleeping disturbances with $7.07 \%$. Then, topographical locations of lesions had a $6.39 \%$ prevalence rate while Lymphadenopathy had the least prevalence rate of $2.93 \%$ (Figure 3).

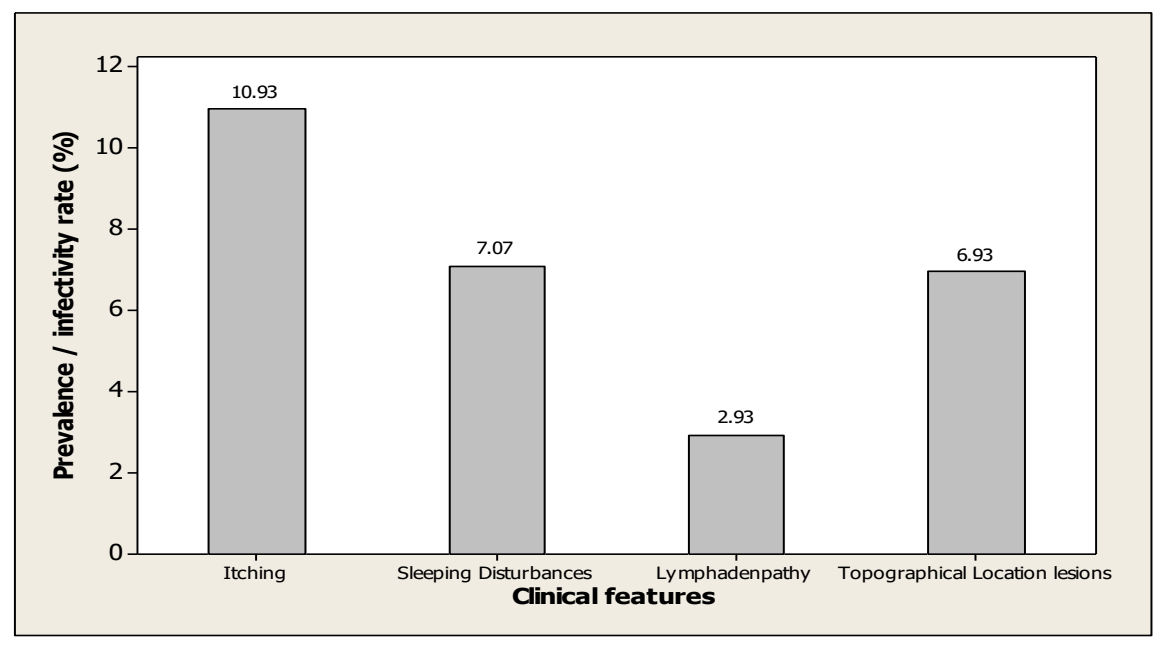

Figure 3 Bar Chart showing the distribution of scabies infections among female students examined based on clinical features 


\subsection{Distribution of scabies based on Topographical locations and lesions among male students examined}

Male students were mainly affected on their armpits with the prevalence rates of $19.6 \%$ followed by the head with a prevalence of $19.2 \%$. The legs had a prevalence rate of $15.6 \%$ and the inter-digital with $15.6 \%$. The elbows and the inguinal / thigh had a prevalence of $13.6 \%$. The abdomen had a prevalence of $11.6 \%$ while the Wrist had the least prevalence rate of $7.6 \%$ (Figure 4 ).

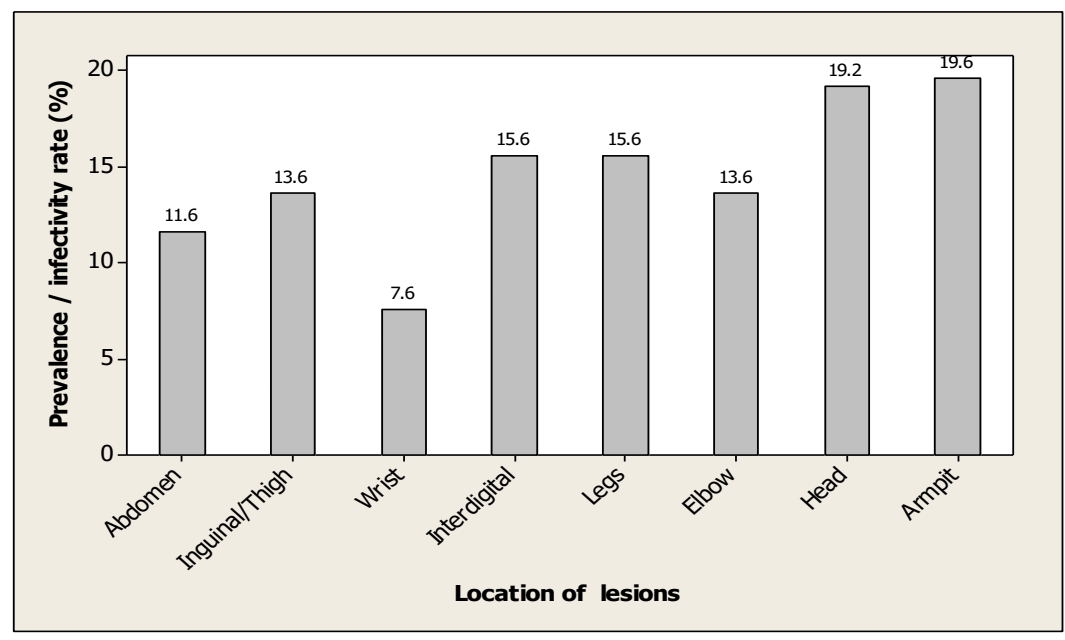

Figure 4 Bar Chart showing the distribution of scabies based on Topographical locations and lesions among male students examined

\subsection{The distribution of scabies based on Topographical locations of lesions among female students examined}

Female students were mostly infected on their Armpits and Abdomen with prevalence rates of $9.60 \%$ each followed by the infections on their inguinal/thigh with prevalence rate of $8.53 \%$. The head had a prevalence rate of $8.28 \%$ and the Interdigital had a prevalence of $2.27 \%$. The legs and the elbows had a prevalence of $4.27 \%$ each. The wrist had the least prevalence rate of $2.93 \%$ (Figure 5 ).

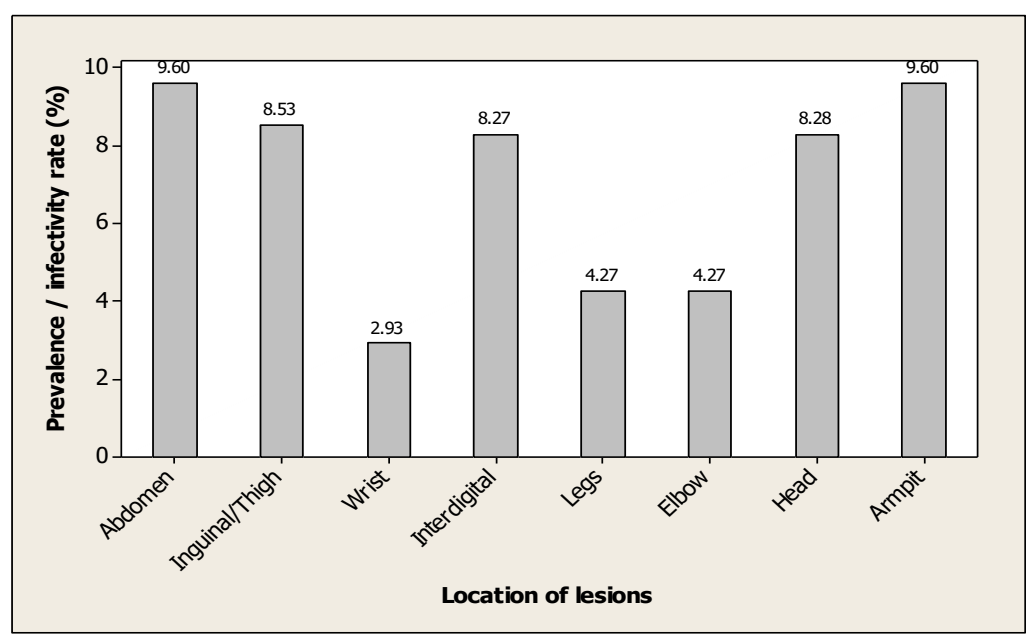

Figure 5 Bar Chart showing the distribution of scabies based on Topographical locations of lesions among female students examined

3.5. Distribution of scabies infection among male students examined based on behaviour and habits by the number of students per room

Male students greater than four per room had the highest infertility rate of $19.5 \%$ than the male Students less than four per room with $14.5 \%$ (Figure 6). 


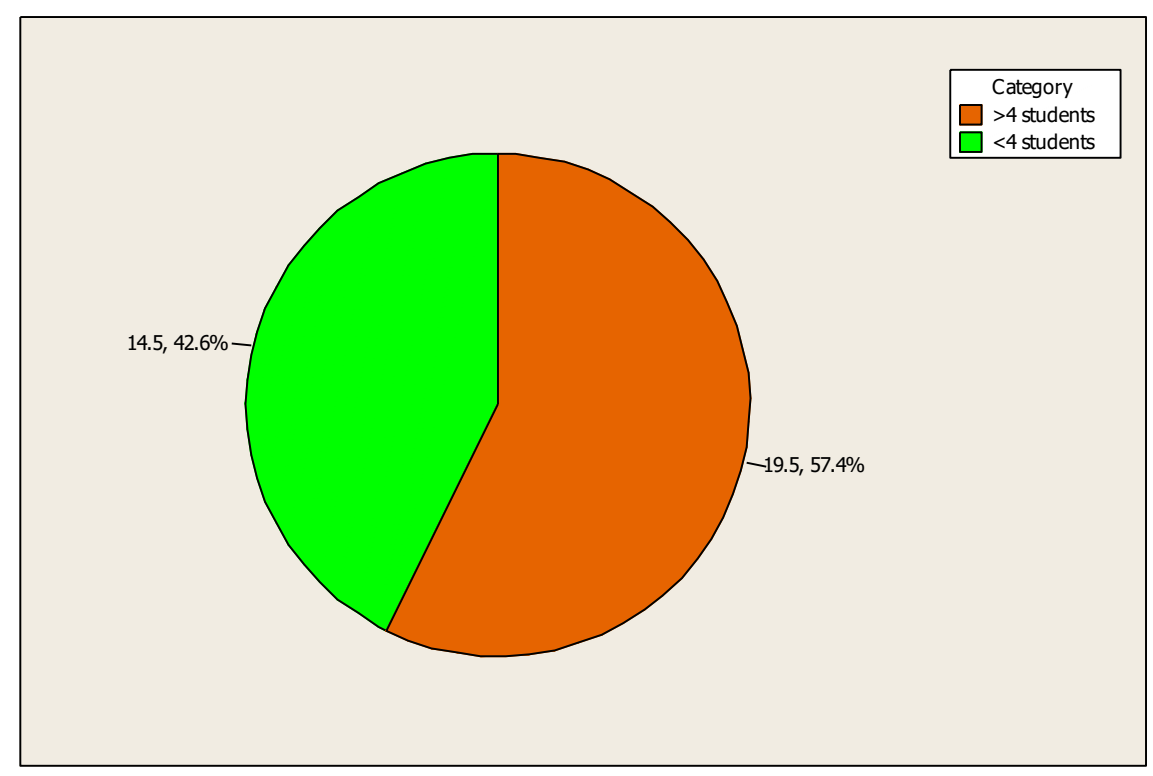

Figure 6 Pie Chart showing the distribution of scabies infection among male students examined based on behaviour and habits by the number of students per room

3.6. Distribution of scabies infection among male students examined based on behaviour and habits by the number that shares beds and pillows

Male students had the highest prevalence rate of $29.0 \%$ with male Students that share beds and pillows while the male Students that don't share beds and pillows had a prevalence rate of $14.5 \%$ (Figure 7 ).

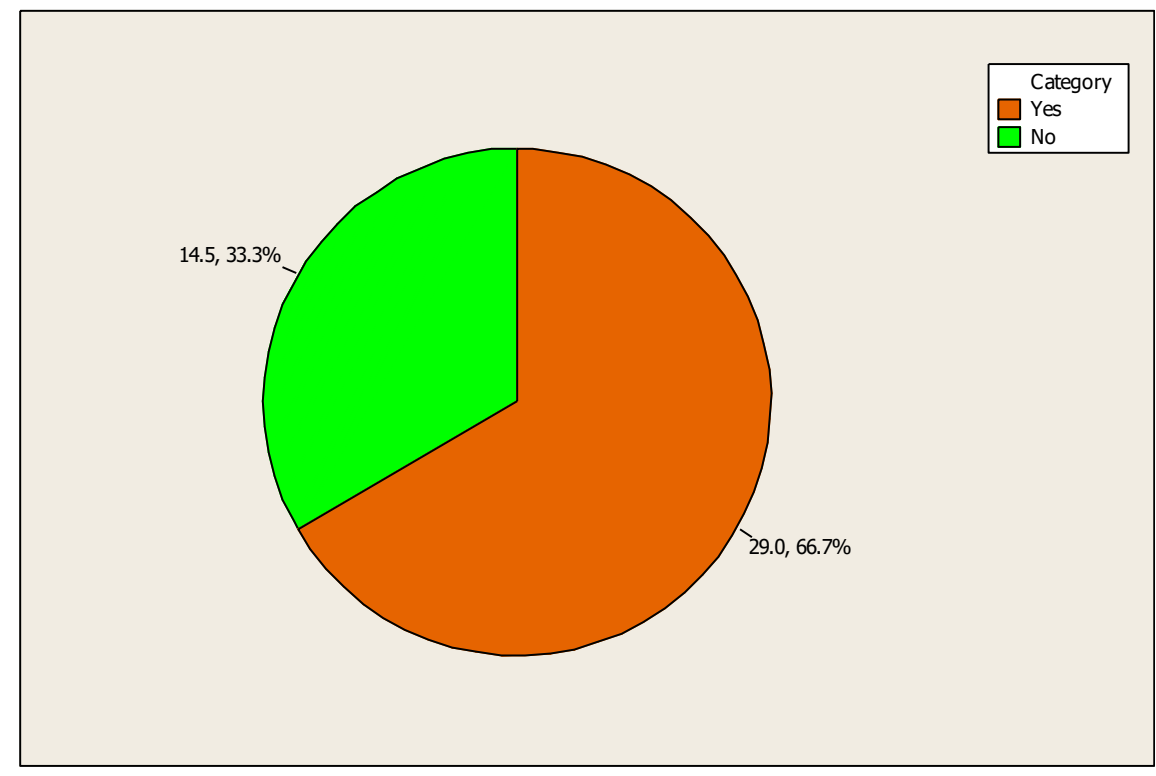

Figure 7 Pie Chart showing the distribution of scabies infection among male students examined based on behaviour and habits by the number that shares beds and pillows

\subsection{Distribution of scabies infection among male students examined based on behaviour and habits by sharing of cloth}

Figure 8 showed that male students examined based on the behaviours and habits by sharing of cloths had a prevalence rate of $19.5 \%$ with Students that share clothes while those that don't share clothes had a prevalence rate of $9.5 \%$ 


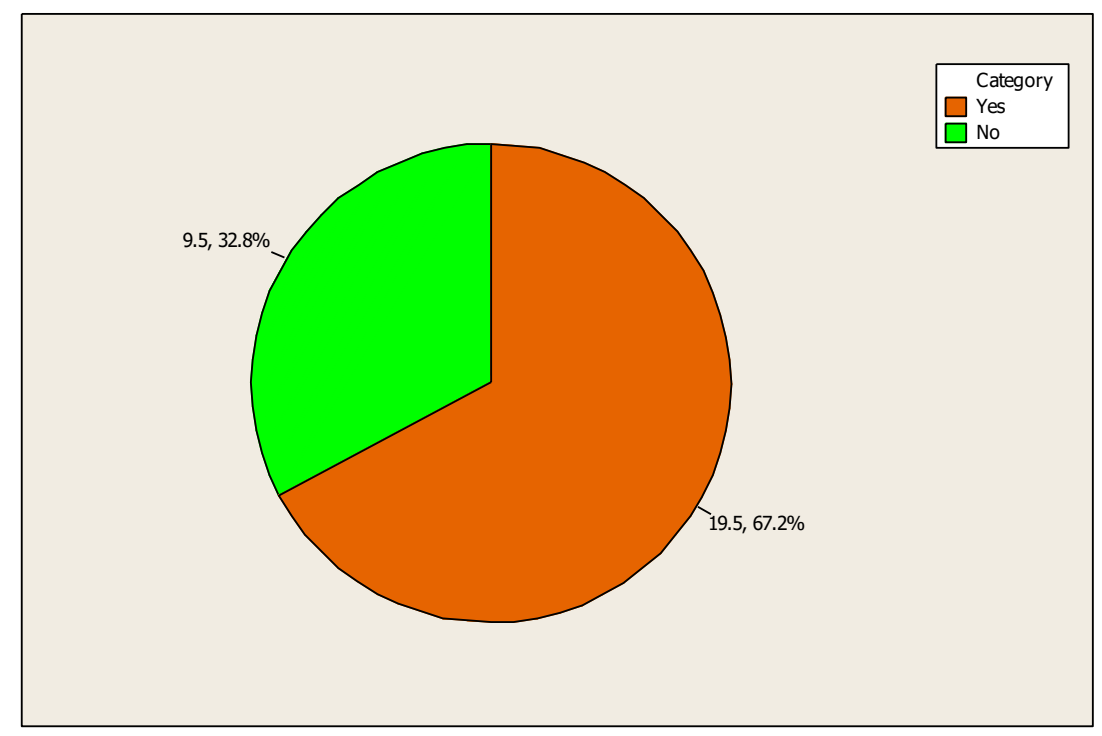

Figure 8 Pie Chart showing the distribution of scabies infection among male students examined based on behaviour and habits by sharing of cloths

\subsection{Distribution of scabies infection among male students examined based on behaviour and habits by} bathing habits

Male Students had the highest rate of $19.5 \%$ for the Students with irregular bathing habits and $10.5 \%$ for the student with regular bathing habits (Figure 9).

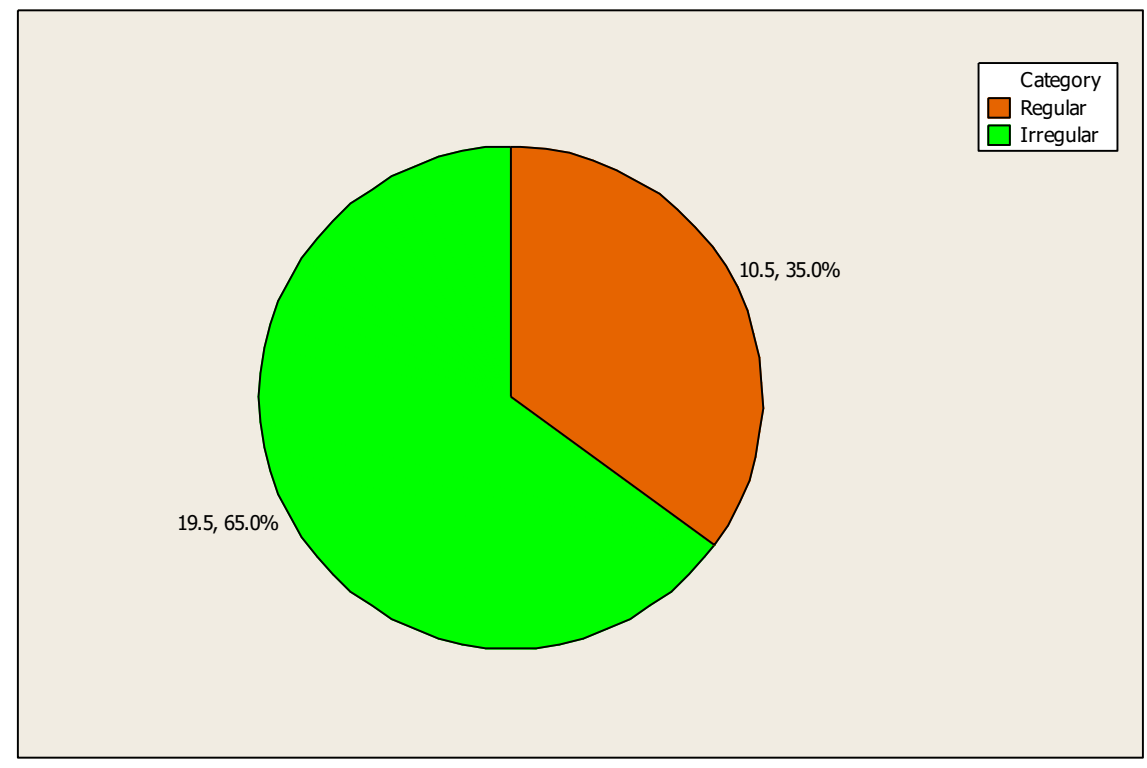

Figure 9 Pie Chart showing the distribution of scabies infection among male students examined based on behaviour and habits by bathing habits

3.9. Distribution of scabies infection among male students examined based on behaviour and habits by use of bathing soap

Male Students had the highest prevalence rate of $9.5 \%$ with students of irregular use of soap bathing habits had recorded $0.0 \%$ for Students with regular bathing with soap habits (Figure 10). 


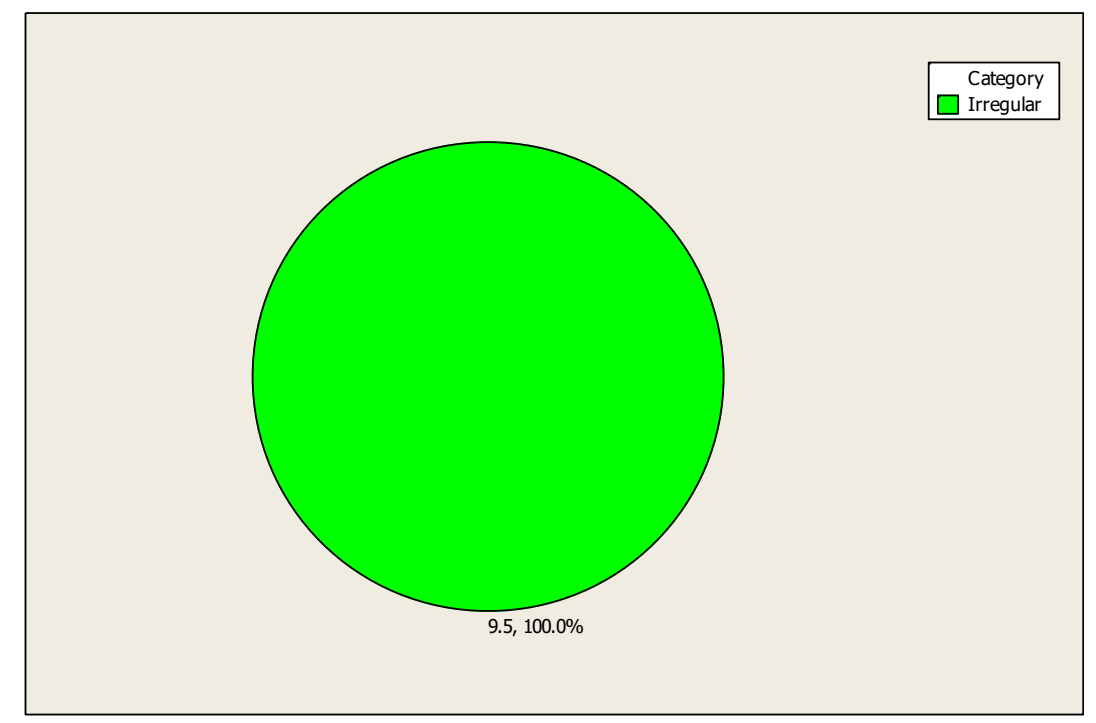

Figure 10 Pie Chart showing the distribution of scabies infection among male students examined based on behaviour and habits by use of bathing soap

\subsection{Distribution of scabies infection among female students examined based on behaviour and habits by the number of students per room}

Female Students examined based on behaviours and habits by the number of Students per room had the highest prevalence rate of $10.33 \%$ with female Students greater than four per room and prevalence student of rate of $3.67 \%$ on female students less than four per room (Figure 11).

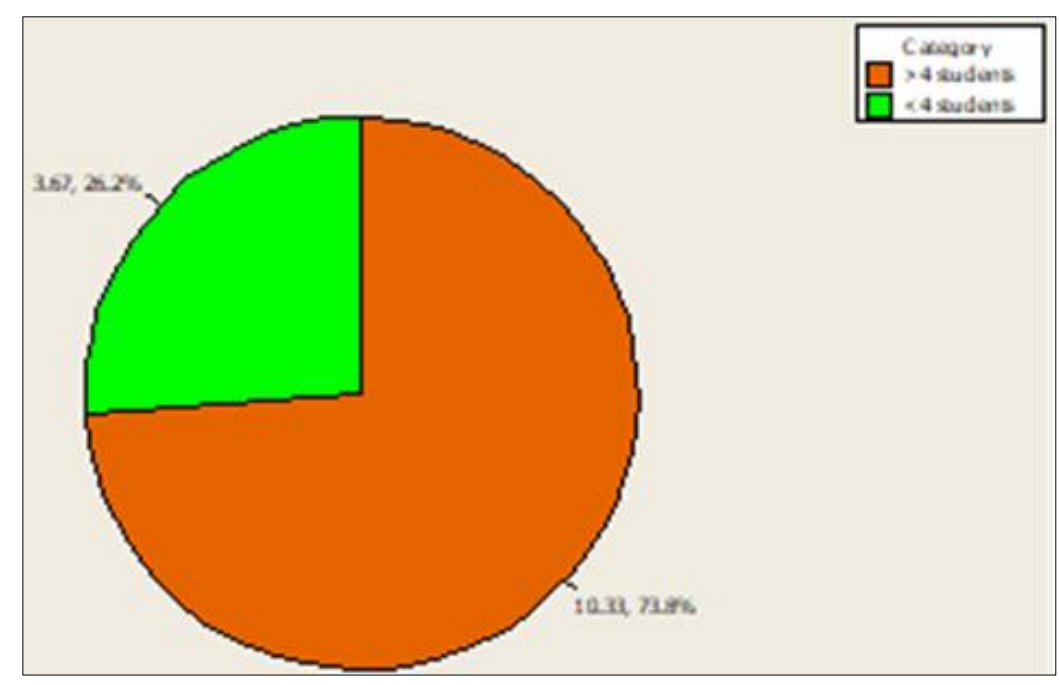

Figure 11 Pie Chart showing the distribution of scabies infection among female students examined based on behaviour and habits by the number of students per room

3.11. Distribution of scabies infection among female students examined based on behaviour and habits by the number that Share beds and pillows

Figure 12 below showed that female students had the highest prevalence rate of $13.67 \%$ with the female Students that share beds and pillows and a prevalence rate of $3.67 \%$ with those female Students that don't share beds and pillows. 


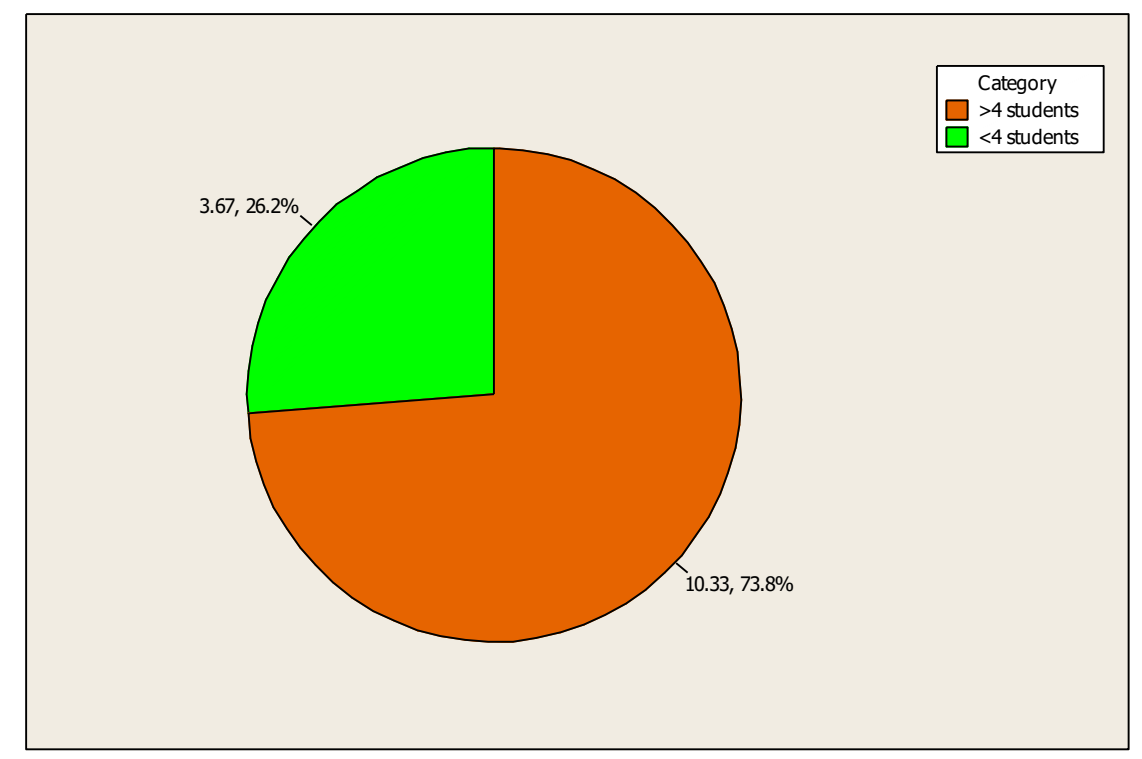

Figure 12 Pie Chart showing the distribution of scabies infection among female students examined based on behaviour and habits by the number that shares beds and pillows

\subsection{Distribution of scabies infection among female students examined based on behaviour and habits by sharing of cloths}

Female students examined based on the behaviours and habits by sharing of cloths had the highest prevalence rate of $10.67 \%$ on female Students that share clothes and prevalence rate of $5.0 \%$ on female Students that don't share cloths (Figure 13).

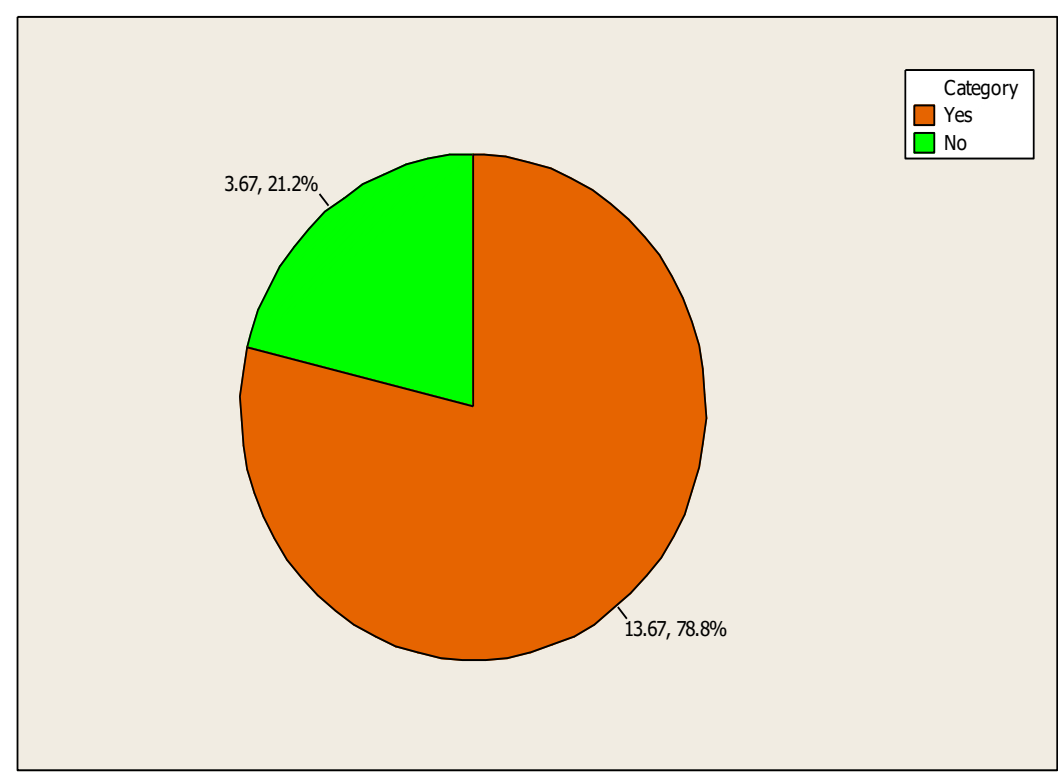

Figure 13 Pie Chart showing the distribution of scabies infection among female students examined based on behaviour and habits by sharing of cloths

\subsection{Distribution of scabies infection among female students examined based on behaviour and habits by} bathing habits

Female students had the highest prevalence rate of $13.67 \%$ on female Students with irregular bathing habits and a prevalence of $3.67 \%$ on female Students with regular bathing habits. 


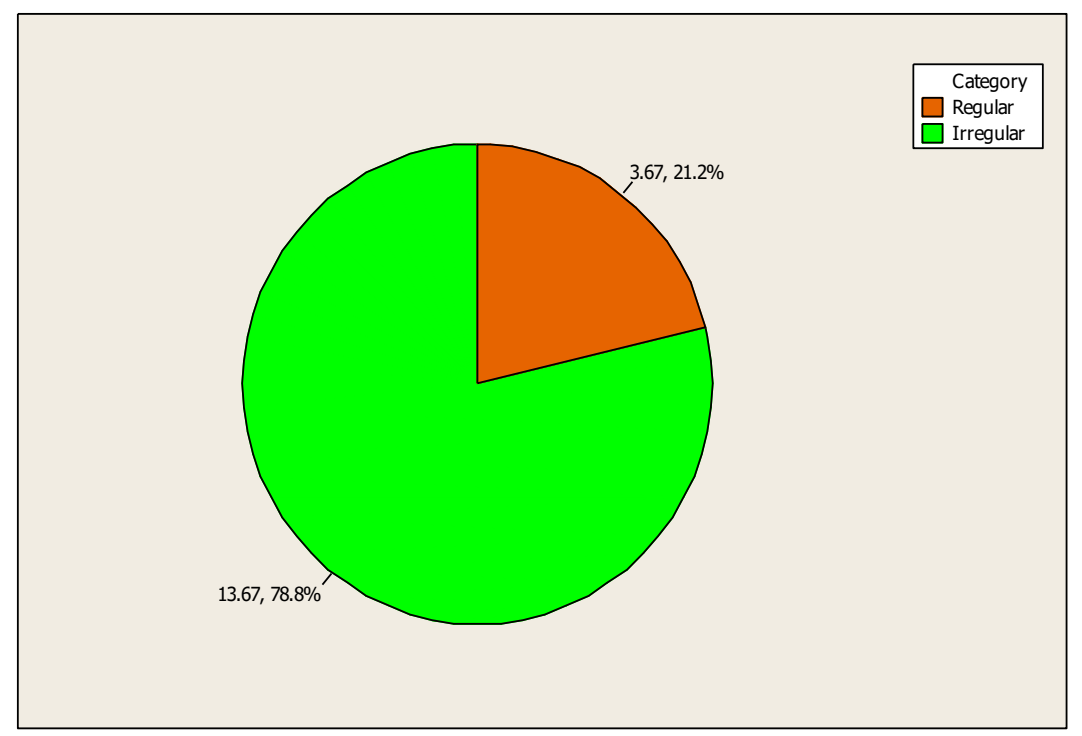

Figure 14 Pie Chart showing the distribution of scabies infection among female students examined based on behaviour and habits by bathing habits

\subsection{Distribution of scabies infection among female students examined based on behaviour and habits by use of bathing soap}

Female students examined had the highest prevalence rate of 5.33\% with the irregular bathing without soap habits and recorded no prevalence rate with the female Students that do bath regularly soap.

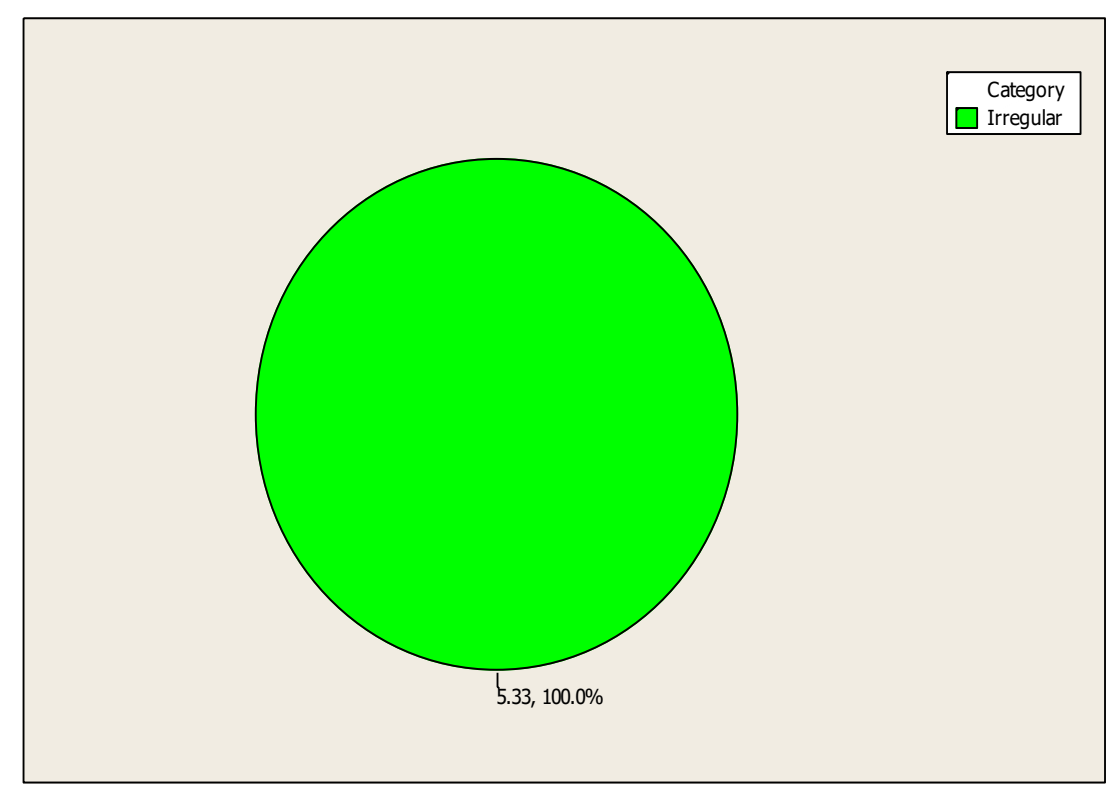

Figure 15 Pie Chart showing the distribution of scabies infection among female students examined based on behaviour and habits by use of bathing soap

\subsection{On the knowledge, attitude and perception}

It was observed that the majority of the participant were not aware of the real cause of scabies infections as they attribute it to ringworms, scratching pimples, witchcraft.

\subsection{On the mode of transmission}

Skin to skin contact with infected students had the highest prevalence. From the findings, the students had little knowledge of the cause of Scabies transmissions. 


\subsection{On the treatment}

It was found that most students in the rural schools do patronize traditional medicine dealers, few consults patent medicine dealers, physicians and pharmacists.

\section{Discussion}

The results obtained from this study showed that male and female students with itchings as clinical features had the highest prevalence rates followed by sleep disturbances. This is in accordance with the findings of [12], [13] and [14].

Male students were mainly infected in their armpits followed by the head, the legs, the inter-digital, the elbows and the inguinal/thigh, the abdomen and then the wrist. This showed that there is a statically significant difference between the distribution of scabies based on topographical locations and lesions among the male students examined. These observations were in line with the research works of [15], [16] and [17].

The result also showed that female students were mostly infected in their armpits and abdomen followed by the infections on their inguinal/thigh, the head, the inter-digitals, the legs and the elbows and then the wrist. This also conforms with the findings of [12] and [18].

The results of the analysis showed that students examined based on their behaviours and habits had the highest prevalence infectivity rates on the sharing of beds and pillows followed by the number of male students greater than 4 per room. Students with irregular bathing habits, sharing of clothes also experienced high infectivity rates. The students that do have their regular bathing habits and students that don't share clothes had a lower prevalence rate than those with irregular bathing habits or shares cloth with others. Students that use soap regularly didn't record any prevalent rate. These findings tally with the research findings of [19], [20] and [21].

\section{Conclusion}

The research work showed that itching and sleeping disturbances had the highest prevalence rates in both the male and female students examined. Early accounts of scabies in humans have documented epidemics of the disease, especially during war periods. There exist a complex relationship between the prevalence of scabies and crowding, hygiene and relative levels of poverty within communities and schools.

\section{Recommendation}

Secondary bacterial infection with potentially serious consequences for the individual health will be averted if the diagnosis is made early and appropriate therapy is instituted.

A high level of the index of suspicion, especially in infants and students who may present with atypical lesions is desirable for proper treatments and control of scabies.

Public health enlightenment campaigns and school/community education programs may help in controlling these emerging epidemics in Anambra State and Nigeria in general.

Given the risk of sequel related to chronic infestation and bacterial superinfection, and infants' response from the health care sector is mandatory. Intervention measures may be integrated into existing helminths control programs based on oral ivermectin mass treatment.

\section{Compliance with ethical standards}

\section{Acknowledgements}

The authors will like to appreciate the research supervisor, research team and the entire staff of the schools used in the study.

\section{Disclosure of conflict of interest}

The authors disclose that there was no conflict of interest as regards the research and publication of this manuscript. 


\section{Statement of informed consent}

Before this project started, a letter of introduction was submitted to the Anambra State Ministry of Education via the Department of Research Studies (Ethical Unit) Awka. The Ministry then gave another Letter of Introduction to the Principals or Authorities of the randomly selected Secondary Schools in the State to enable the research works accordingly. Oral consent also was obtained from the students before they were recruited for the study. The participants were assured that the information collected will be treated with the utmost confidentiality and for the research work only.

\section{References}

[1] Arlian LG, MS Morgan, SA Estes, SF Walton, DJ Kemp, BJ Curric. Circulating IgE in patients with ordinary and crusted scabies. Journal Med. Entomol.2004; 41: 74-77.

[2] Arlian LG, MS Morgan, JS Neal. Extracts of scabies mites (Sarcoptidae: Sarcoptes scabiei) modulate cytokine expression by human peripheral blood mononuclear cells and dendritic cells. Journal Med. Entomol. 2004; 41: 69-73.

[3] Yahaya H. Change in pattern of skin disease in Kaduna, North Central Nigeria. Int. Journal Dermatol. 2007; 46: 936-943.

[4] Altraide DD, Akpa MR, George O. The pattern of skin disorders in a Nigerian tertiary hospital. Journal Public Health Epidemiol. 2011; 3: 177-181.

[5] Amro A, Hamarsheh O. Epidemiology of scabies in the West Bank, Palestinian Territories (Occupied). Int Journal Infect Dis. 2012; 16: 202-236.

[6] Arlian LG, MS Morgan, JS Ncal. Modulation of cytokine expression in human keratinocyies and fibroblasts by extracts of scabies mites. Am. Journal Trop. Med. Hyg. 2003; 69: 652- 656.

[7] Roberts LJ, SE Huffam, SF Walton, BJ Currie. Crusted scabies: clinical and immunologies! findings in seventy-eight patients and a review of the literature. Journal Infect. 2015; 50: 375-381.

[8] Worth C, Heukelbach J, Fengler G, Walter B, Liesenfeld O, Feldmeier H. Impaired quality of life in adults and children with scabies from an impoverished community in Brazil. Int. Journal Dermatol. 2012; 51: 275-282.

[9] Rapp CM, MS Morgan, LG Arlian. Presence of host immunoglobulin in the gut of Sarcoptes scabiei (Acan: Sarcoptidae). Journal Med. Entomol. 2006; 43: 539-542.

[10] Arlian LG, DL Vyszenski-Moher. Life cycle of Sarcopties scabiei var canis. Journal Parasitol. 1988; 74: 427-430.

[11] Romani L, Steer AC, Whitfeild MJ, Kaldor J. Prevalence of scabies and impetigo worldwoide: A systematic review. Lancet Infect Dis. 2015; 15: 960.

[12] Hay RJ, Steer AC, Engelman D, Walton S. Scabies in the developing world-its prevalence, complications and management. Clin Microbiol Infect. 2012; 18: 313 -323.

[13] Johnston G, Sladden M. Scabies: Diagnosis and treatments. Int. Journal Dermatol. 2005; 331: 619-622.

[14] Ugbomoiko US, Ofoezie IF, Heulkelbach J. Tungiasis: High prevalence, parasite load and morbidity in a rural community in Lagos Nigeria. Int. Journal Dermatol. 2007; 46: 475-481.

[15] Nnoruka EN. Skin disese in South East Nigeria: A current perspective. Int. Journal Dermatol. 2005; 44: 29-33.

[16] Kouotou EA, Nansseu JR, Kouawa MK, Bissek AC. Prevalence and drivers of human scabies among children and adolescents living and study in Cameroonian boarding schools. Parasite Vectors. 2016; 9: 400.

[17] Heulekbach J, Mazigo HD, Ugbomoiko US. Impact of scabies in resource poor communities. Curr Opin Infect Dis. 2013; 26: 127-32.

[18] Hegab DS, Keto AM, Kabbas IA, Dabish GM. Scabies among primary school children in Egypt: Sociomedical environmental study in Kafr EL- Sheikh administrative area. Chin. Cosmet. Investing. Dermatol. 2015; 8: 105.

[19] Chosidow O. Scabies. N. Engl. Journal Med. 2006; 354: 17181727.

[20] Jackson A, Heukelbach J, Juniour C, Feldmeier H. Clinical features and associated morbidity of scabies in a rural community in Alagoas, Brazil. Trop. Med. Int. Health. 2007; 12: 493- 502.

[21] Heulekbach JSF. Walton. and 11. Feldmder. I-clopaiawtic infes ᄀtations. Cun. Infect. Dis Rep. 2005; 7: 373-380. 